Check for updates

Cite this: RSC Adv., 2019, 9, 1602

\title{
The modification mechanism and the effect of magnesium chloride on poly(vinyl alcohol) films
}

\begin{abstract}
Wenhao Du, ${ }^{\text {ab }}$ Li Jiang, ${ }^{\text {ab }}$ Mengke Shi, ${ }^{\text {ab }}$ Zhaojie Yang ${ }^{\text {ab }}$ and Xi Zhang (D) *ab
The modification mechanism and the effect of $\mathrm{MgCl}_{2}$ on poly(vinyl alcohol) and the effect of water in the system were studied in this paper. The effect of $\mathrm{MgCl}_{2}$ on different fully dried PVA was investigated by Fourier transform infrared spectroscopy, X-ray diffraction, differential scanning calorimeter, thermogravimetric analysis, water content test, dynamic thermomechanical analysis and tensile test, respectively. The results showed that $\mathrm{MgCl}_{2}$ was an effective strengthening agent, which could crosslink with PVA and then effectively decrease the crystallinity of PVA. With the addition of $\mathrm{MgCl}_{2}$, the strength and rigidity of PVA increased and the melting temperature decreased. The effect of $\mathrm{MgCl}_{2}$ on thermal stability of PVA was related to the alcoholysis degree of PVA. The tensile strength of PVA films modified with $\mathrm{MgCl}_{2}$ were all over $120 \mathrm{MPa}$. Moreover, the effect of $\mathrm{MgCl}_{2}$ on the dynamic thermomechanical properties and tensile properties of PVA with various content of water was studied. Water could interact with $\mathrm{MgCl}_{2}$ to destroy the crosslink between $\mathrm{MgCl}_{2}$ and PVA. In the presence of water, PVA modified with $\mathrm{MgCl}_{2}$ became soft, with lower tensile strength and higher elongation at break.
\end{abstract}

Received 4th December 2018

Accepted 31st December 2018

DOI: 10.1039/c8ra09958h

rsc.li/rsc-advances salts could play a role as heterogeneous nucleating agent of PVA to increase the crystallinity of PVA. ${ }^{8}$ This indicated that with the addition of suitable inorganic salts, it could be expected to prepare PVA with predetermined crystallinity. From then on, the studies of modifying PVA with various kinds of inorganic salts increase gradually. ${ }^{9-12} \mathrm{MgCl}_{2}$ was always considered as a plasticizer of the system in previous studies. However, the effect of water could not be ignored. Thence, the modification mechanism of inorganic salts on PVA remains to further investigation.

Generally, water has a great influence on the properties of PVA films. Water could play a role as plasticizer by forming interaction with the $-\mathrm{OH}$ of PVA molecule chains. Lots of researches have been investigating the effect of water on PVA. ${ }^{3,4,13,14}$ However, these studies always focused on the state of water in PVA, the destroying mechanism and the plasticization of water on the crystal of PVA. ${ }^{15-18}$ The effect of water on mechanical properties of PVA and the effect of water in the process of modification of PVA with inorganic salts rarely get attention.

The aim of this paper is to study the way of $\mathrm{MgCl}_{2}$ influencing PVA by investigating the effect of $\mathrm{MgCl}_{2}$ on the structure and properties of PVA with different alcoholysis degree and polymerization degree after sufficient drying. In addition, the effect of water in the system was studied in this paper. It could be excepted that the modification mechanism of other inorganic salts could be revealed and PVA with more excellent properties could be prepared based on this study.
${ }^{a}$ State Key Laboratory of Polymer Materials Engineering, Chengdu 610065, People's Republic of China. E-mail: zhangxi6352@163.com; Tel: +8613808072562

${ }^{b}$ Polymer Research Institute of Sichuan University, Chengdu 610065, People's Republic of China 


\section{Experimental}

Materials

PVA1799 (DP = 1700, degree of hydrolysis 99\%), PVA1788 (DP = 1700 , degree of hydrolysis $88 \%$ ), PVA1792 (DP $=1700$, degree of hydrolysis 92\%), PVA2488 (DP $=2400$, degree of hydrolysis $88 \%$ ) and PVA2499 (DP = 2400, degree of hydrolysis 99\%), were provided by Sichuan Vinylon Factory, SINOPEC (China). $\mathrm{MgCl}_{2} \cdot 6 \mathrm{H}_{2} \mathrm{O}$ was purchased from Kelong Chemical Co. (Chengdu, China), which was used without any further purification.

\section{Sample preparation}

PVA films were prepared by the casting method. First, $5 \mathrm{~g}$ PVA and $2 \mathrm{wt} \%, 4 \mathrm{wt} \%, 6 \mathrm{wt} \%, 8 \mathrm{wt} \%, 10 \mathrm{wt} \%, 12 \mathrm{wt} \%$ and $15 \mathrm{wt} \%$ $\mathrm{MgCl}_{2} \cdot 6 \mathrm{H}_{2} \mathrm{O}$ were dissolved in distilled water by heating in an oil bath at $90{ }^{\circ} \mathrm{C}$ for $3 \mathrm{~h}$, and the aqueous solutions were prepared, which called the film-forming solution. The filmforming solutions were casted onto the Petri-dish and dried at $60{ }^{\circ} \mathrm{C}$ for $48 \mathrm{~h}$ to eliminate water completely. According to the content of $\mathrm{MgCl}_{2} \cdot 6 \mathrm{H}_{2} \mathrm{O}$, the PVA1799 films were called as PVA, PM2, PM4, PM6, PM8, PPM10, PM12 and PM15; the PVA1788 films were called as $880,884,886,888,8810$ and 8815 ; the PVA1792 films were called as 1792-0, 1792-4, 1792-10 and 179215; the PVA2488 films were called as 2488-0, 2488-4, 2488-10, 2488-15.

Fully dried sample preparation: the film-forming solutions were coated on the PTFE sheet and dried at $60{ }^{\circ} \mathrm{C}$ for $48 \mathrm{~h}$. All samples were dried at $105{ }^{\circ} \mathrm{C}$ for $5 \mathrm{~h}$ under vacuum $(P<0.3$ $\mathrm{MPa})$.

Sample with different water content preparation: PVA, PM4, PM6, PM8 and PM10 were dried at $105{ }^{\circ} \mathrm{C}$ for $5 \mathrm{~h}$ under vacuum $(P<0.3 \mathrm{MPa})$. Then these films were stored at the environment of high humidity to prepare PVA films with $4 \%$ and $12 \%$ content water.

\section{Characterizations}

Fourier transform infrared (FT-IR) spectroscopy. The infrared spectra were measured using a Fourier transform infrared spectrophotometer (Nicolet 560). The film-forming solutions prepared according to Table 1 was casted on a Petri dish and dried at $60{ }^{\circ} \mathrm{C}$ to remove water. The measurements were carried out with a resolution of $4 \mathrm{~cm}^{-1}$.

X-ray diffraction (XRD) measurements. The XRD test was carried out using an X'Pert Pro MPD diffractometer manufactured by Philips Analytical Company of Netherlands, with nickel filter $\mathrm{Cu} \mathrm{K} \alpha$ as the radiation source. The acceleration voltage was $50 \mathrm{kV}$ and the current was $35 \mathrm{~mA}$. The samples were continuously scanned over the $2 \theta$ range from 5 to $50^{\circ}$

Differential scanning calorimetry (DSC). The DSC measurements were performed by a differential scanning calorimeter (NETZSCHDSC204). Samples total weight of 5-7 mg were weighted and were heated from $30{ }^{\circ} \mathrm{C}$ to $250{ }^{\circ} \mathrm{C}$ at a rate of $10{ }^{\circ} \mathrm{C} \min ^{-1}$ under a flow of nitrogen.

Thermal gravity analysis (TGA). TGA was performed by SDTQ600 TGA thermal analysis instrument (Du Pont). The samples for testing were heated from room temperature to $600{ }^{\circ} \mathrm{C}$ at a heating rate of $10{ }^{\circ} \mathrm{C} \mathrm{min}^{-1}$.

Dynamic thermomechanical analysis (DMA). The dynamic mechanical measurements were carried out with DMA Q800 (TA, USA). The samples were cut as a dimension of $15.0 \mathrm{~mm} \times$ $4.0 \mathrm{~mm} \times 0.3 \mathrm{~mm}$. The oscillatory frequency was $1 \mathrm{~Hz}$. The temperature was raised from -50 to $150^{\circ} \mathrm{C}$ at a constant rate of $3{ }^{\circ} \mathrm{C} \min ^{-1}$.

Mechanical testing. The mechanical properties (tensile strength (TS), elongation at break (\%Eb) and Young's modulus) of the film was determined using a tensile testing equipment (Instron 5567). The crosshead speed was $20 \mathrm{~mm} \mathrm{~min}^{-1}$. The initial gauge length of the specimen was $20 \mathrm{~mm}$. The width of each tensile sample was $4 \mathrm{~mm}$. The film thickness was measured with a micrometer in triplicate. The samples were placed in an air environment at a relative humidity of $54 \%$ for one week before measurement. The required relative humidity was obtained by placing a saturated $\mathrm{Mg}\left(\mathrm{NO}_{3}\right)_{2}$ solution in a sealed box at $25{ }^{\circ} \mathrm{C}$. The data were the average of 5-7 specimens.

Water absorption testing. The samples were dried at $105{ }^{\circ} \mathrm{C}$ for $5 \mathrm{~h}$ and were stored in constant temperature and constant humidity box (SANTN HTC-500) at $25{ }^{\circ} \mathrm{C}$ and a relative humidity of $54 \%$. The films were weighed every $12 \mathrm{~h}$ and the water content were calculated based on the quality of PVA. The water content (WA) was obtained using the relationship.

$$
\mathrm{WA}=\frac{W_{\mathrm{e}}-W_{\mathrm{d}}}{W_{\mathrm{d}}} \times 100 \%
$$

$W_{\mathrm{e}}$ was the weight of the films after storing at the $\mathrm{RH}$ of $54 \%$ for one week, $W_{\mathrm{d}}$ was the weight of the films after drying sufficiently.

\section{Results and discussion}

\section{FT-IR analysis}

FT-IR was used to characterize the PVA1799 and PVA 1788 films before and after $\mathrm{MgCl}_{2}$ modification, and the results were shown in Fig. 1. In the IR spectrum, the peak at $3000-3500 \mathrm{~cm}^{-1}$ corresponds to the stretching vibration of $-\mathrm{OH}$ on PVA

Table 1 DSC analysis of thermal characteristic of PVA1799 and PVA1788 with various contents of $\mathrm{MgCl}_{2} \cdot 6 \mathrm{H}_{2} \mathrm{O}$

\begin{tabular}{lccccccccccc}
\hline & PVA & PM4 & PM6 & PM8 & PM10 & PM12 & 880 & 884 & 886 & 888 \\
\hline$T_{\mathrm{g}} /{ }^{\circ} \mathrm{C}$ & 67.8 & 76.9 & 92.1 & 81.5 & 80.4 & 76.8 & 69.8 & 69.8 & 87.8 & 93.2 \\
$T_{\alpha} /{ }^{\circ} \mathrm{C}$ & 139 & 145 & 143 & 146 & 145 & 149 & 116 & 115 & 141 & 97.4 \\
$T_{\mathrm{m}} /{ }^{\circ} \mathrm{C}$ & 228 & 226 & 219 & 221 & 214 & 203 & 196 & 193 & Double peak & Double peak
\end{tabular}



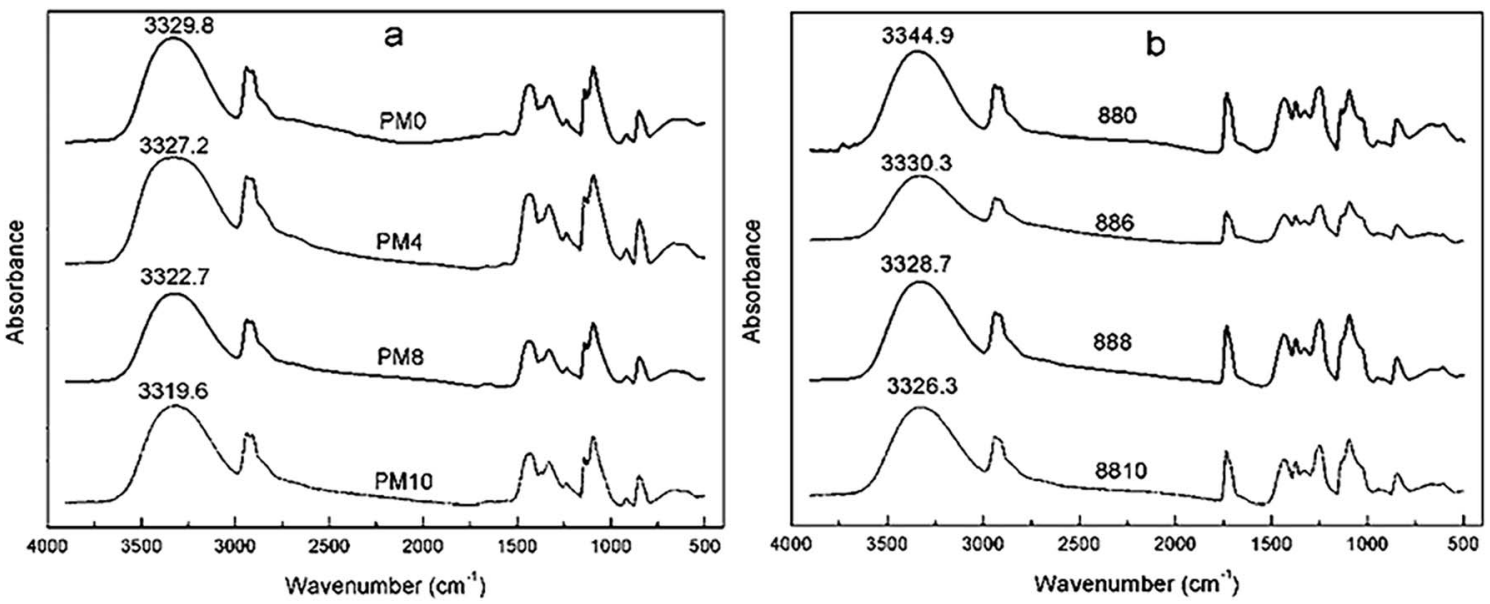

Fig. 1 The FT-IR spectra of PVA1799 (a) and PVA1788 (b) with various contents of $\mathrm{MgCl}_{2} \cdot 6 \mathrm{H}_{2} \mathrm{O}$.

molecules, the peaks at 2942, 1430 and $1096 \mathrm{~cm}^{-1}$ are the characteristic of symmetric stretching vibration of $\mathrm{C}-\mathrm{H}$ and bending stretching of $\mathrm{CH}_{2}$ and stretching vibration of $\mathrm{C}-\mathrm{O}$, respectively. ${ }^{19}$ Due to the lower degree of alcoholysis, there are a large number of ester groups on PVA1788 molecules. Thus, the carbonyl stretching vibration of ester groups at $1733 \mathrm{~cm}^{-1}$ could be found in the FT-IR spectra of PVA1788. It could be seen from Fig. 1(a) and (b) that PVA films exhibited a decrease in frequencies after the addition of $\mathrm{MgCl}_{2}$. This is because the electron interaction between $\mathrm{Mg}^{2+}$ and oxygen atom of $-\mathrm{OH}$ in PVA molecules was stronger than intermolecular and intramolecular hydrogen bonds of PVA. Therefore, $\mathrm{MgCl}_{2}$ could weak the hydrogen bonds. As a result, the absorption frequency of hydroxyl group of PVA1799 and PVA1788 shifted $10 \mathrm{~cm}^{-1}$ and $18 \mathrm{~cm}^{-1}$ to a lower wavenumber with the addition of $10 \mathrm{wt} \%$ $\mathrm{MgCl}_{2} \cdot 6 \mathrm{H}_{2} \mathrm{O}$. The difference might arise from the different number of -OH in PVA1788 and PVA1799. There were less -OH in PVA1788, so that the percent of -OH on PVA1788 which could interact with $\mathrm{MgCl}_{2}$ was higher than that of PVA1799.

\section{Crystalline properties}

The X-ray diffraction patterns of PVA1799 and PVA1788 films before and after $\mathrm{MgCl}_{2}$ modification were displayed in Fig. 2(a) and (b). It could be seen that the diffraction peak of PVA appears at $2 \theta=20^{\circ}(d=0.46 \mathrm{~nm})$ and the diffraction peaks of PVA film decreased in intensity with the increasing of $\mathrm{MgCl}_{2}$ content. This phenomenon indicated that $\mathrm{MgCl}_{2}$ had a damaging effect on the crystals of PVA. This is because that $\mathrm{MgCl}_{2}$ could form strong interaction with PVA molecules and this interaction could interrupt the hydrogen bonding in the crystalline structure of PVA. The previous work has proved that the area under the diffraction peak or its intensity could be taken as a measurement of the degree of crystallinity. The decrease of the intensity of the diffraction peak indicated that the addition of $\mathrm{MgCl}_{2}$ could effectively decrease the degree of crystallinity of PVA films. It could also be noticed that the diffraction peaks of $\mathrm{MgCl}_{2}$ did not appear in the patterns. This also suggests that $\mathrm{MgCl}_{2}$ was completely dissolved in PVA films and no $\mathrm{MgCl}_{2}$ crystals or congregates existed.
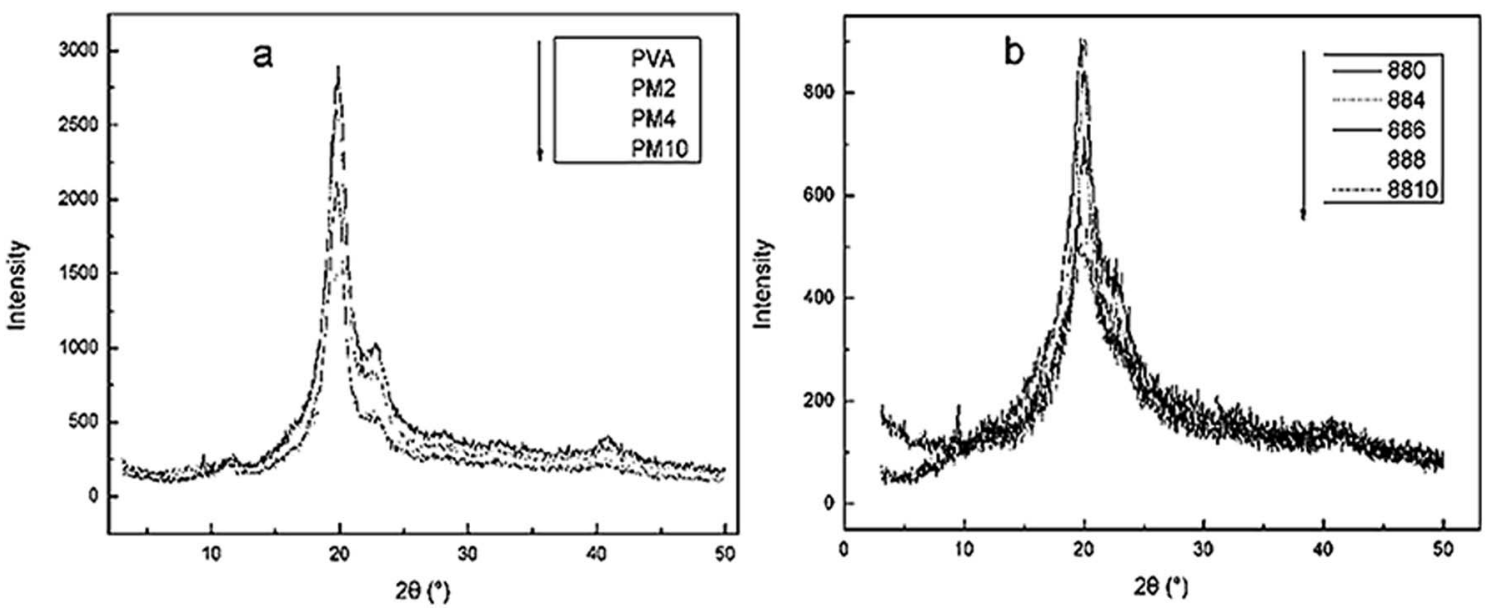

Fig. 2 The XRD curves of PVA1799 (a) and PVA1788 (b) with various contents of $\mathrm{MgCl}_{2} \cdot 6 \mathrm{H}_{2} \mathrm{O}$. 

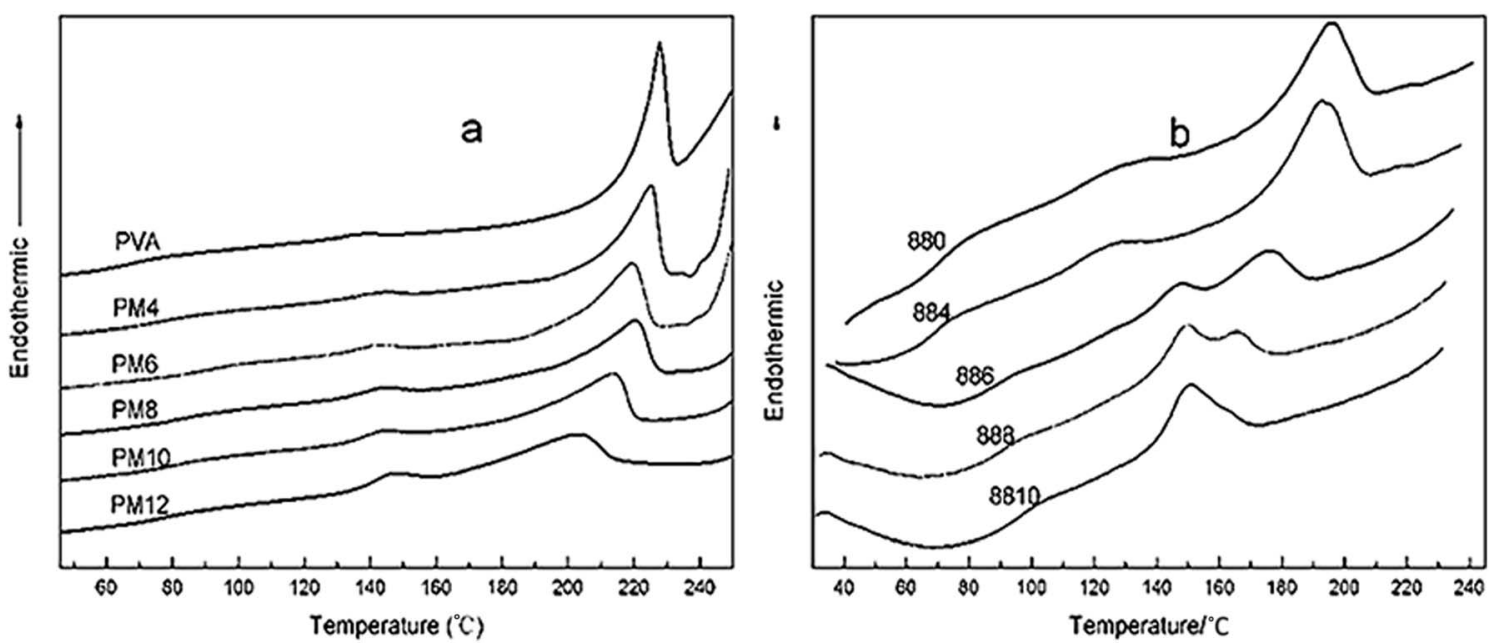

Fig. 3 The DSC curves of PVA1799 (a) and PVA1788 (b) with various contents of $\mathrm{MgCl}_{2} \cdot 6 \mathrm{H}_{2} \mathrm{O}$.

\section{Thermal properties}

The DSC curves of PVA films modified with various contents of $\mathrm{MgCl}_{2} \cdot 6 \mathrm{H}_{2} \mathrm{O}$ are displayed in Fig. 2, and the corresponding data are shown in Table 1.

With the increasing of $\mathrm{MgCl}_{2}$ content, both the $T_{\mathrm{g}}$ value of PVA1799 and PVA1788 increased. This is because $\mathrm{MgCl}_{2}$ could crosslink with PVA as Fig. 4 to some extent. This interaction between $\mathrm{MgCl}_{2}$ and PVA could weak the activity of PVA chain segments. $T_{\alpha}$ is the temperature at which chain segments of amorphous region near crystal region in PVA begin to motion. It could be found that the $T_{\alpha}$ value of PVA1799 increased with the increasing of content of $\mathrm{MgCl}_{2}$. This might be due to the influence of $\mathrm{MgCl}_{2}$ on crystal orientation and crystallinity of PVA. ${ }^{8}$ Moreover, this influence could be reflected by the change of melting peak. It could be seen from Fig. 3(a) that increasing content of $\mathrm{MgCl}_{2}$ decreased melting point, broadened melting peak and melting range. ${ }^{20}$ This indicated that the crystal structure of PVA was destroyed and the distribution of the crystal size became wider after the addition of $\mathrm{MgCl}_{2}$. In the case of PVA1788, with the addition of over $4 \mathrm{wt} \% \mathrm{MgCl}_{2}$ content, the melting peak of PVA1788 turned from single peak to double peak and moved forward low temperature. While with the

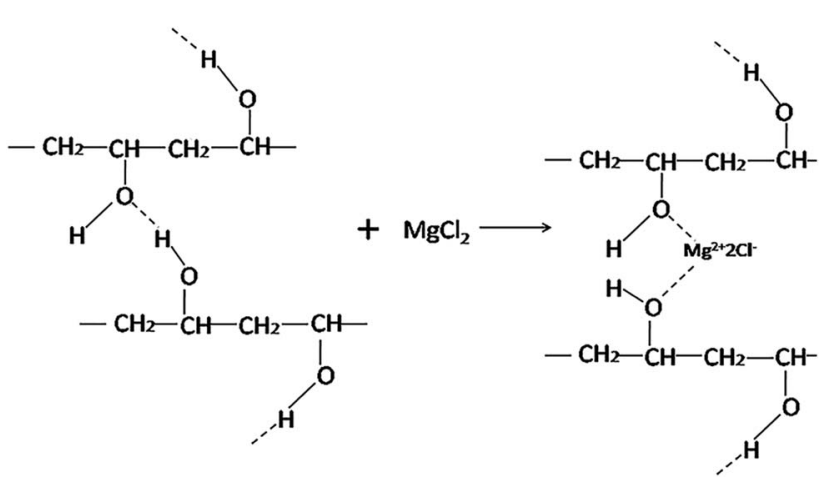

Fig. 4 The interaction between $\mathrm{MgCl}_{2}$ and PVA. addition of $10 \mathrm{wt} \% \mathrm{MgCl}_{2}$ content, the melting peak became single peak and the melting temperature decreased form $45{ }^{\circ} \mathrm{C}$ of pure PVA1788 to $151{ }^{\circ} \mathrm{C}$. This proved that the effect of $\mathrm{MgCl}_{2}$ on PVA1788 was higher than PVA1799.

In addition, the effect of $\mathrm{MgCl}_{2}$ on the thermal stability of PVA1799 and PVA1788 were studied. The thermal degradation of PVA could mainly be divided into two steps. Firstly, $-\mathrm{OH}$ and $-\mathrm{OCOCH}_{3}$ were eliminated to form $\mathrm{H}_{2} \mathrm{O}$ and $\mathrm{CH}_{3} \mathrm{COOH}$. In the second step, the main chain of PVA broke and some organic volatiles were produced. ${ }^{21,22}$ It could be seen from Fig. 5, with the addition of $4 \mathrm{wt} \% \mathrm{MgCl}_{2} \cdot 6 \mathrm{H}_{2} \mathrm{O}$, the $T_{\mathrm{i}}$ (the initial thermal decomposition temperature) and $T_{\max 1}$ (the temperature of the biggest decomposition rate in the first step) increased from $237{ }^{\circ} \mathrm{C}, 256{ }^{\circ} \mathrm{C}$ of pure PVA1799 to $259{ }^{\circ} \mathrm{C}$ and $270{ }^{\circ} \mathrm{C}$, respectively. Meanwhile, with the increasing dosage of $\mathrm{MgCl}_{2} \cdot 6 \mathrm{H}_{2} \mathrm{O}$, the $T_{\mathrm{i}}$ and $T_{\max 1}$ increased constantly. This indicated that $\mathrm{MgCl}_{2}$ could increase the thermal stability of PVA1799. From Fig. 5(c) and (d) it could be seen that the temperature of two steps of pure PVA1788 were nearly the same, which was different with PVA1799. With the addition of $4 \mathrm{wt} \% \mathrm{MgCl}_{2} \cdot 6 \mathrm{H}_{2} \mathrm{O}$, the TGA curve was basically in coincidence with that of pure PVA1788. However, when the dosage of $\mathrm{MgCl}_{2} \cdot 6 \mathrm{H}_{2} \mathrm{O}$ reached $10 \mathrm{wt} \%$, the first step moved toward the lower temperature. In addition, with the increase of the dosage of $\mathrm{MgCl}_{2} \cdot 6 \mathrm{H}_{2} \mathrm{O}$, the thermal stability of PVA1788 decreased constantly. Thus, the effect of $\mathrm{MgCl}_{2}$ $\cdot 6 \mathrm{H}_{2} \mathrm{O}$ on the thermal stability of PVA1792, PVA2488 and PVA2499 were studied to figure out the law of $\mathrm{MgCl}_{2}$ on the thermal stability of PVA.

\section{Thermal stability analysis}

The effect of $\mathrm{MgCl}_{2} \cdot 6 \mathrm{H}_{2} \mathrm{O}$ on the thermal stability of PVA1792, PVA2488 and PVA2499 were studied and the obtained TGA and DTG curves were shown in Fig. 6 . The $T_{\mathrm{i}}$ and $T_{\max 1}$ of PVA with different alcoholysis degree and polymerization degree before and after modifying with $\mathrm{MgCl}_{2}$ were recorded in Table 2 .

For PVA1792, PVA1788 and PVA 2488 with low alcoholysis degree, both the $T_{\mathrm{i}}$ and $T_{\max 1}$ of them were substantially the 

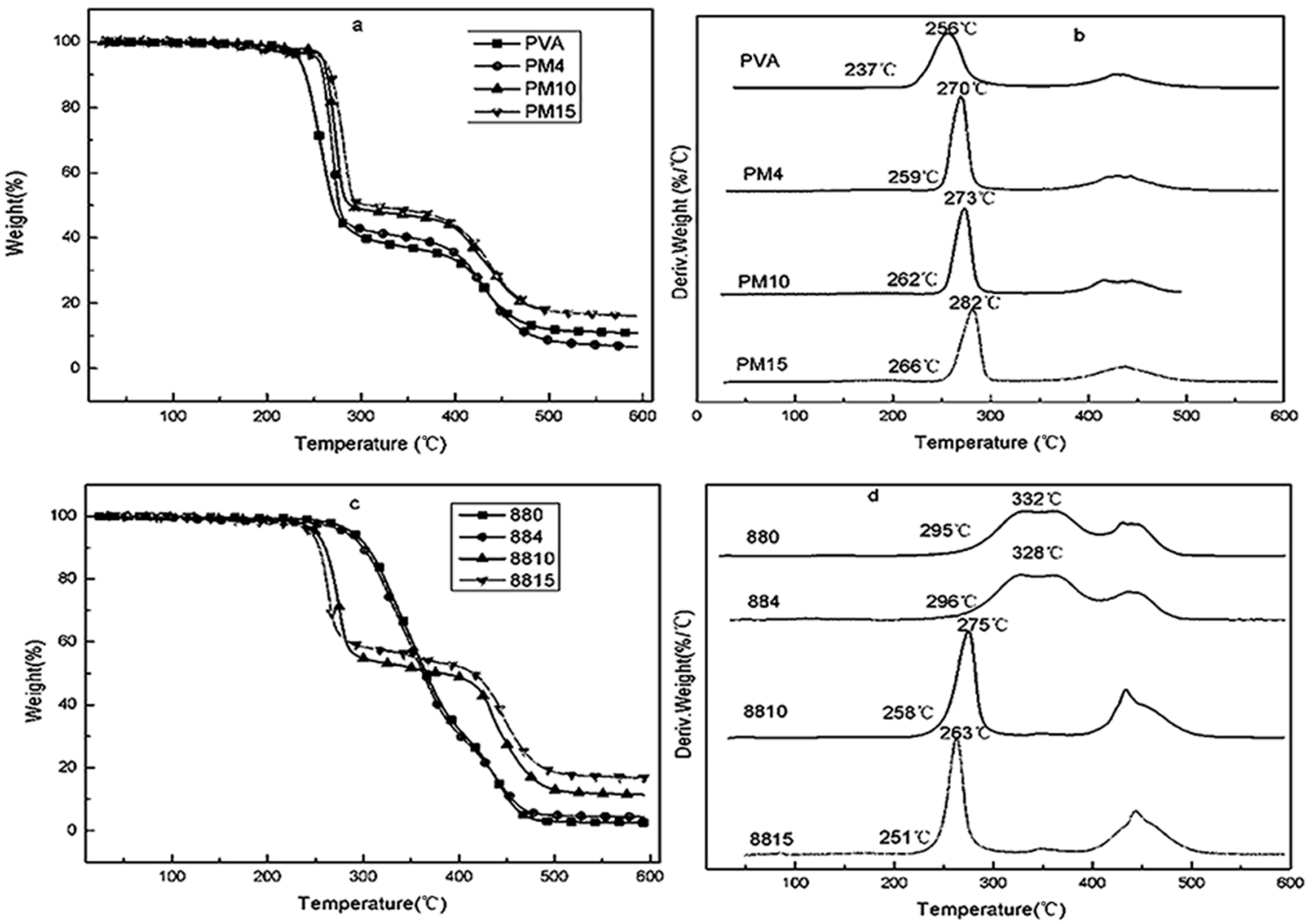

Fig. 5 The TG and DTG curves of PVA1799 ( $\mathrm{a}$ and b) and PVA1788 ( $\mathrm{c}$ and d) with various contents of $\mathrm{MgCl}_{2} \cdot 6 \mathrm{H}_{2} \mathrm{O}$.
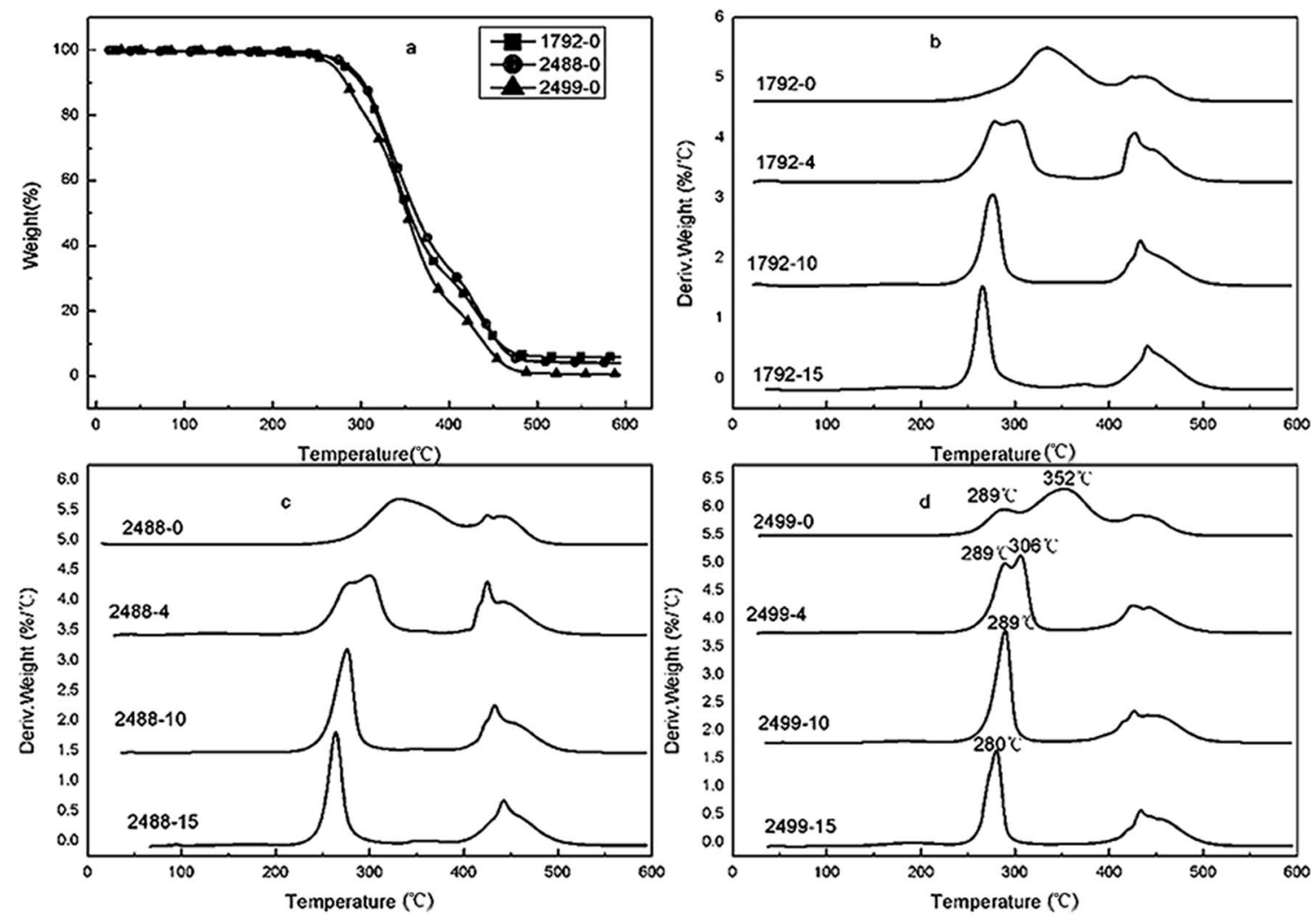

Fig. 6 The TG (a) and DTG curves of PVA1792 (b), PVA2488 (c) and PVA2499 (d) with various contents of $\mathrm{MgCl}_{2} \cdot 6 \mathrm{H}_{2} \mathrm{O}$. 
Table 2 The initial and the first maximum decomposition temperature of different types of PVA

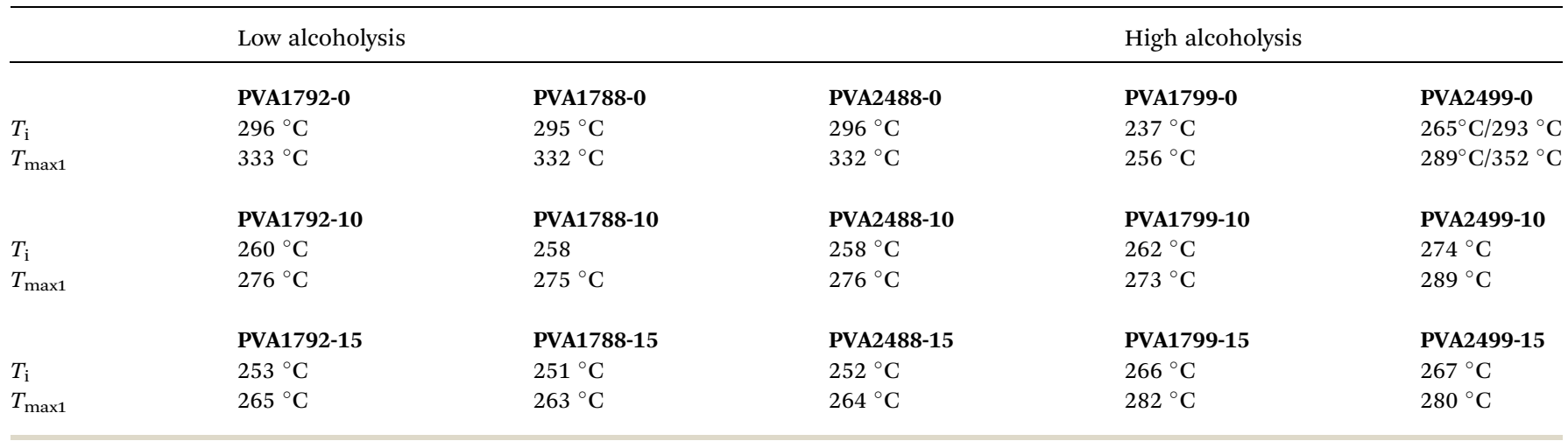

same. With the addition of $10 \mathrm{wt} \% \mathrm{MgCl}_{2} \cdot 6 \mathrm{H}_{2} \mathrm{O}$, the $T_{\mathrm{i}}$ and $T_{\max 1}$ of PVA1792, PVA1788 and PVA 2488 decreased from about $295{ }^{\circ} \mathrm{C}, 332{ }^{\circ} \mathrm{C}$ to $260{ }^{\circ} \mathrm{C}$ and $276{ }^{\circ} \mathrm{C}$ or so. While with the addition of $15 \mathrm{wt} \%$, the $T_{\mathrm{i}}$ and $T_{\max 1}$ would decrease to lower values. This indicated that $\mathrm{MgCl}_{2}$ could decrease the thermal stability of PVA with low alcoholysis degree, which was independent of the polymerization degree of PVA. This is probably because there were lots of residual ester groups in PVA with low alcoholysis degree. These ester groups had an effect on the interaction between $\mathrm{MgCl}_{2}$ and the -OH of PVA. As a result, hydroxyl and ester groups would remove at a lower temperature.

However, the effect of $\mathrm{MgCl}_{2}$ on PVA with higher alcoholysis degree was different with above situation. For PVA2499 with higher polymerization degree, there were two decomposition peaks in the first step at $289^{\circ} \mathrm{C}$ and $352{ }^{\circ} \mathrm{C}$, respectively. This is maybe because the residual ester groups showed an uneven distribution, thus the alcoholysis degree was higher than $99 \%$ in some parts but lower than 99\% in other parts of PVA2499. According to the above analysis, it could be seen that the $T_{\max 1}$ of PVA with lower alcoholysis degree was $332{ }^{\circ} \mathrm{C}$. Thence, the peaks of the first step corresponded to the HA (decomposition of high alcoholysis parts) and LA (decomposition of low alcoholysis parts). With the addition of $4 \mathrm{wt} \% \mathrm{MgCl}_{2} \cdot 6 \mathrm{H}_{2} \mathrm{O}$, the $T_{\max 1}$ of HA had no changes, but the $T_{\max 1}$ of LA decreased from
$352{ }^{\circ} \mathrm{C}$ of pure PVA2499 to $306{ }^{\circ} \mathrm{C}$. While with the addition of $10 \mathrm{wt} \%$ and $15 \mathrm{wt} \% \mathrm{MgCl}_{2} \cdot 6 \mathrm{H}_{2} \mathrm{O}$, there was only one peak in the first decomposition step at $289{ }^{\circ} \mathrm{C}$ and $280{ }^{\circ} \mathrm{C}$, respectively. Oppositely, for PVA1799 with lower polymerization degree, increasing dosage of $\mathrm{MgCl}_{2}$ increased the $T_{\mathrm{i}}$ and $T_{\max 1}$. This indicated that the effect of $\mathrm{MgCl}_{2}$ on PVA with high alcoholysis was related to the polymerization degree of PVA: the addition of $\mathrm{MgCl}_{2}$ could increase the thermal stability of PVA with low polymerization degree. In the case of PVA with high polymerization degree, the effect of $\mathrm{MgCl}_{2}$ on the thermal stability of PVA with high polymerization degree was complicated, because the ester groups showed an uneven distribution resulting in various alcoholysis degree on PVA molecules.

\section{Dynamic mechanical properties}

DMA was used to study the $\tan \delta$ and storage modulus $\left(G^{\prime}\right)$ of PVA1799 and PVA1788. $\tan \delta$ is a damping term defined as the ration of energy dissipated as heat to the maximum energy stored in the materials. It is an index of the material viscoelasticity. It could be seen from Fig. 7 that the $\tan \delta$ values of PVA increased as the $\mathrm{MgCl}_{2}$ content increased from $4 \mathrm{wt} \%$ to $10 \mathrm{wt} \%$. This indicated that with the increasing content of $\mathrm{MgCl}_{2}$, the viscoelasticity of PVA increased. The size of the tan $\delta$
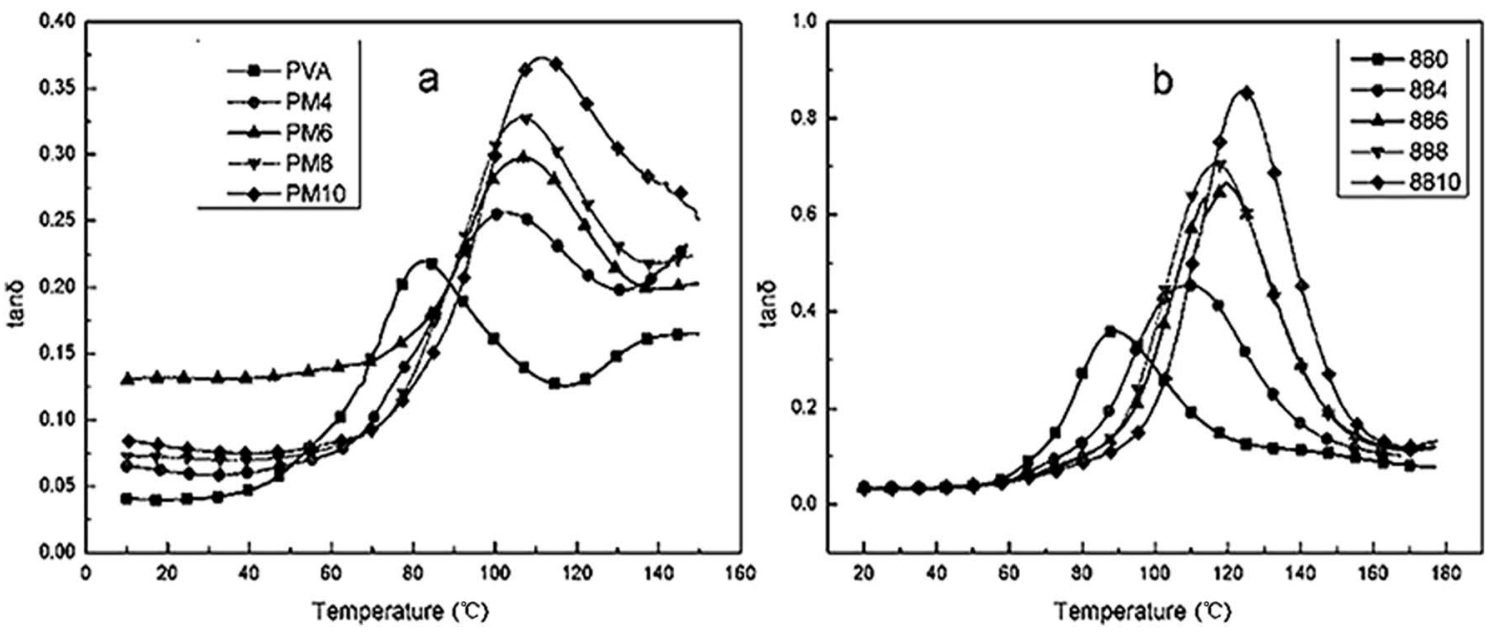

Fig. 7 Plots of $\tan \delta$ against temperature of PVA1799 (a) and PVA1788 (b) with various contents of $\mathrm{MgCl}_{2} \cdot 6 \mathrm{H}_{2} \mathrm{O}$. 

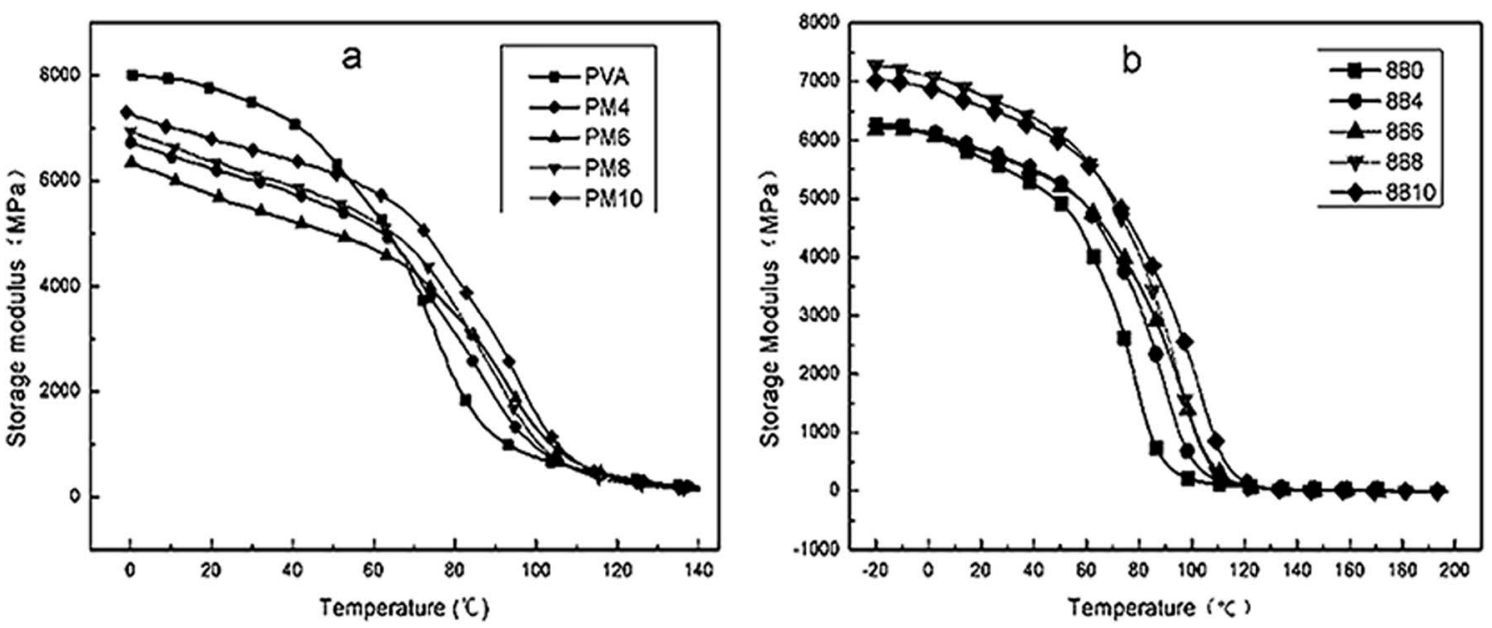

Fig. 8 Plots of storage modulus $E^{\prime}$ against temperature of PVA1799 (a) and PVA1788 (b) with various contents of $\mathrm{MgCl}_{2} \cdot 6 \mathrm{H}_{2} \mathrm{O}$.

peak is believed to relate to the volume fraction of the material undergoing the transition. It could be found that the peak size of $\tan \delta$ increased with the increasing content of $\mathrm{MgCl}_{2}$. This was because the destroy of $\mathrm{MgCl}_{2}$ on the crystals would increase the amorphous fraction and the relaxation time of chain segments. The peak temperature of the $\tan \delta$ curve is determined as the $T_{\mathrm{g}}$ of the polymer material. It could be found that the $T_{\mathrm{g}}$ of PVA increased with the addition of $\mathrm{MgCl}_{2}$. This is probably because that the $\mathrm{Mg}^{2+}$ could crosslink with the $-\mathrm{OH}$ of PVA, which limited the chain movement of PVA resulting in the improvement of $T_{\mathrm{g}}$.

$G^{\prime}$ is a measurement of the rigidity of the material. Fig. 8 showed the plots of $G^{\prime}$ versus temperature of PVA1799 and PVA1788. The $G^{\prime}$ of PVA1799 and PVA1788 decreased as the temperature increased. This was because increasing temperature could destroy the intermolecular and intramolecular hydrogen bonds of PVA and crosslinking between $\mathrm{MgCl}_{2}$ and PVA resulting in the decrease of chain rigidity. Moreover, it could be seen from Fig. 8(a) that the descending speed of pure PVA1799 was higher than that of PVA1799 modified with $\mathrm{MgCl}_{2}$. When the temperature was low, $G^{\prime}$ of pure PVA was higher than

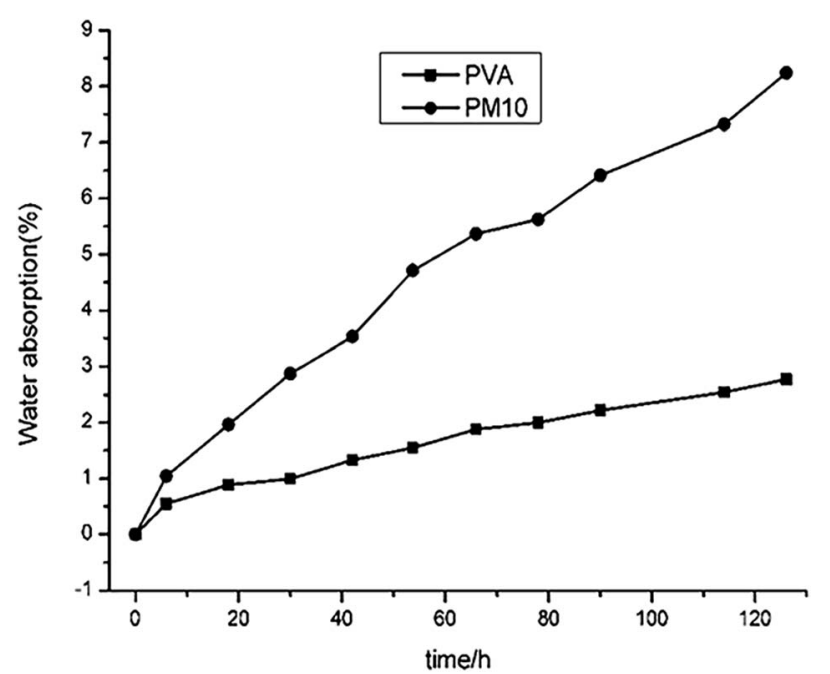

Fig. 10 The water absorption of PVA and PM10.
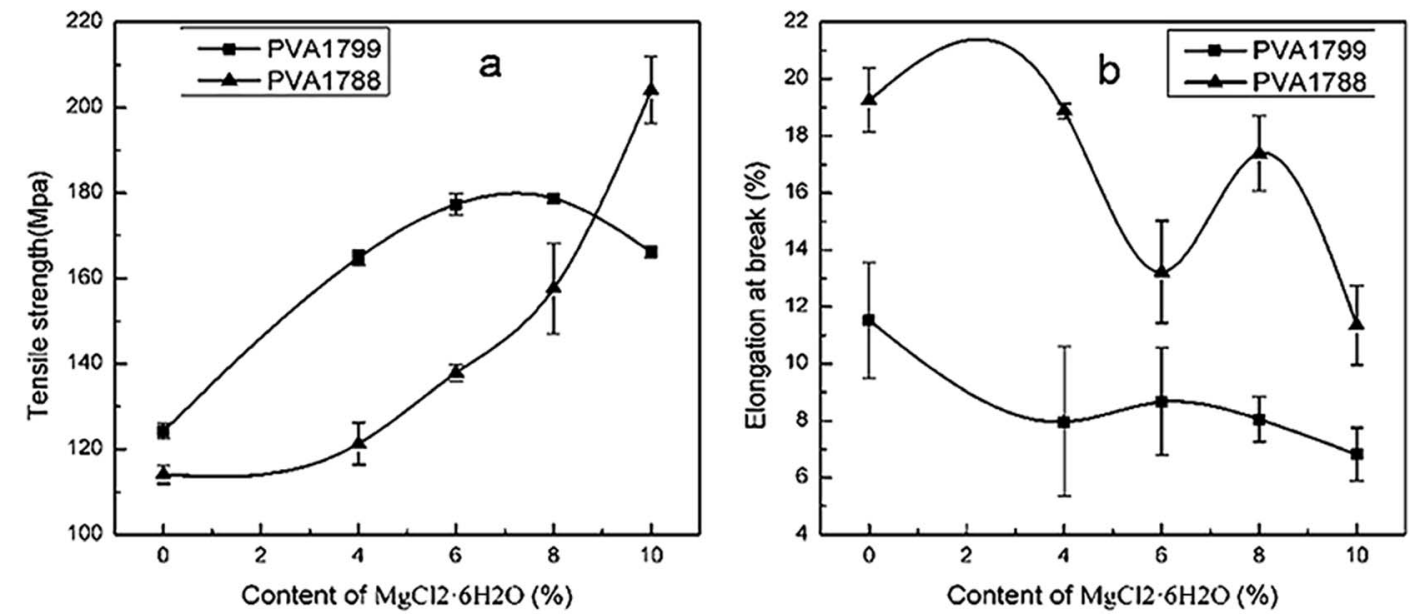

Fig. 9 The tensile strength (a) and elongation at break (b) of PVA1799 and PVA1788 with various contents of $\mathrm{MgCl}_{2} \cdot 6 \mathrm{H}_{2} \mathrm{O}$. 

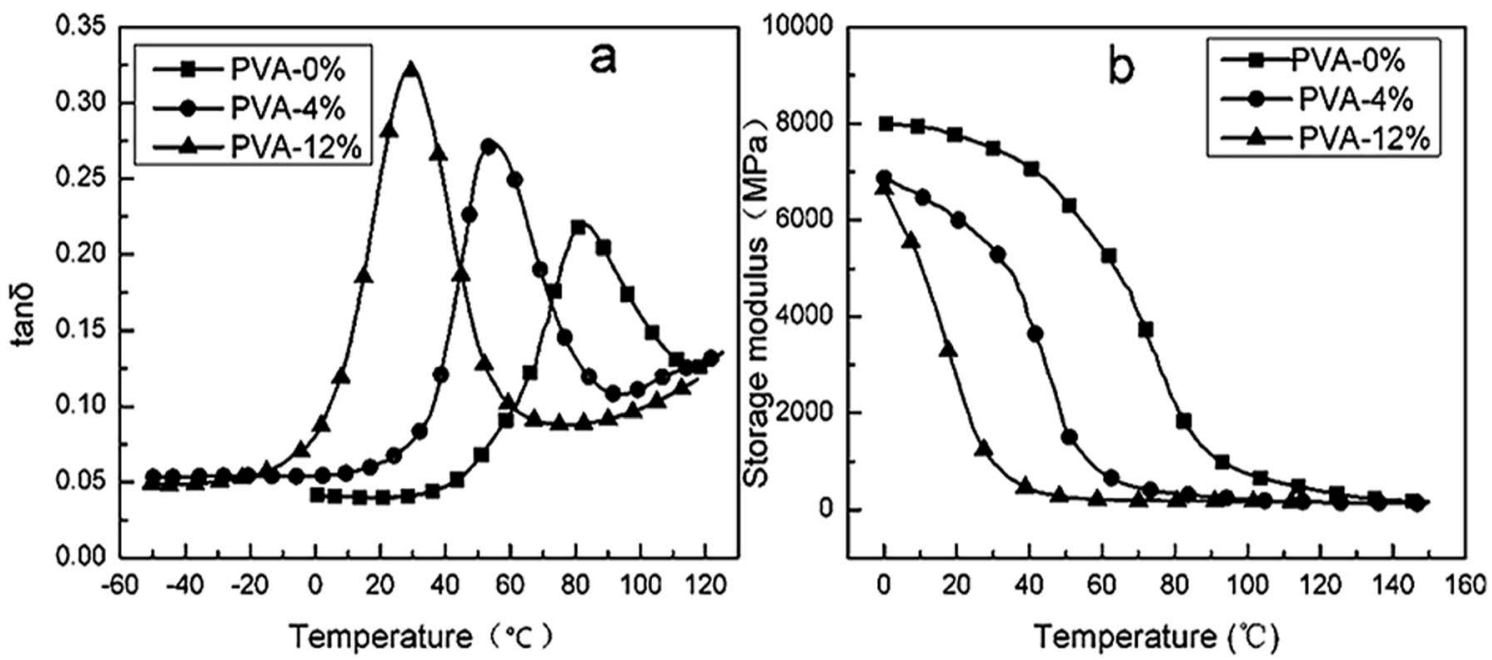

Fig. 11 Plots of $\tan \delta$ and storage modulus $G^{\prime}$ against temperature of PVA with $0,4 \%, 12 \%$ content of water.

that of PM, but it became the opposite as the temperature increased. This might be due to the high alcoholysis degree and high regularity arise from high density hydrogen bonds. PVA1799 had higher crystallinity and thus crystallinity was the main factor to influence $G^{\prime}$. However, crystal of PM was destroyed by $\mathrm{MgCl}_{2}$. As the temperature increased, crystal of pure PVA was destroyed, but there was crosslink between $\mathrm{Mg}^{2+}$ and PVA in $\mathrm{MgCl}_{2}$ modified PVA1799 resulting in high thermomechanical stability. For PVA1788 with low alcoholysis degree and low crystallinity, crystallinity had little influence on $G^{\prime}$. Thus, the crosslink between $\mathrm{MgCl}_{2}$ and PVA1788 was the main influence factors on $G^{\prime}$. Thence, $G^{\prime}$ of PVA1788 was greater than or equal to that of pure PVA1788.

\section{Mechanical properties}

The influence of $\mathrm{MgCl}_{2} \cdot 6 \mathrm{H}_{2} \mathrm{O}$ on the mechanical properties of PVA1799 and PVA1788 was evaluated by tensile testing. Fig. 9 showed the measured values of tensile strength and elongation at break of PVA1799 and PVA1788 before and after modified with various content of $\mathrm{MgCl}_{2}$. After the addition of $\mathrm{MgCl}_{2}$, the tensile strength increased, while the elongation at break decreased. This proved that $\mathrm{MgCl}_{2}$ was an effective strengthening agent, which could improve the strength and rigidity of PVA. The strengthening effect of $\mathrm{MgCl}_{2}$ on PVA could be evaluated by the slope of curves in Fig. 9(a). With the increasing content of $\mathrm{MgCl}_{2}$, the slope of PVA1799 decreased while the slope of PVA1788 increased. This indicated that the strengthening effect of $\mathrm{MgCl}_{2}$ on PVA1788 was higher than that of PVA1799. This is because that the high crystallinity played a major role in increasing the tensile strength of PVA1799. $\mathrm{MgCl}_{2}$ could destroy the crystal but crosslink with PVA. As a result, the strengthening effect of $\mathrm{MgCl}_{2}$ on PVA1799 decreased with the increasing content of $\mathrm{MgCl}_{2}$. While the content of $\mathrm{MgCl}_{2}$ reached 8\%wt, the tensile strength did not increase any more. For PVA1788 with low crystallinity, the
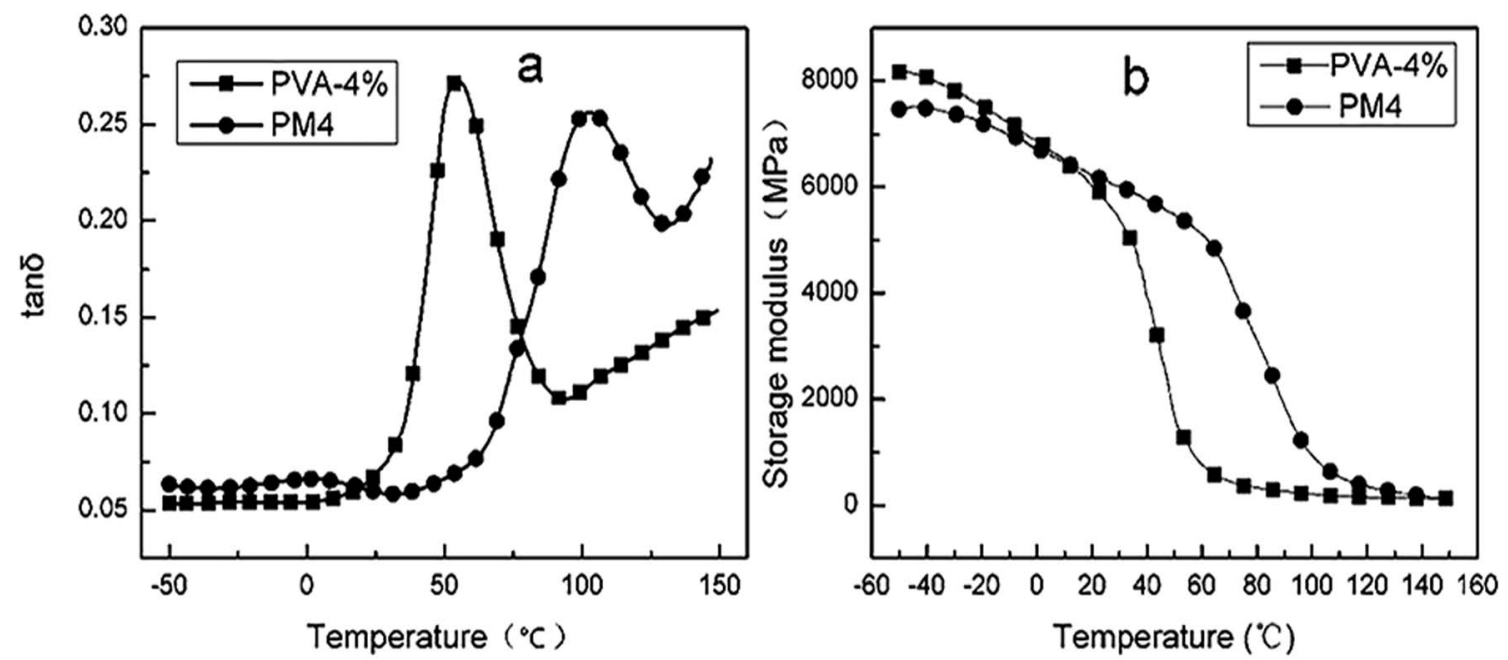

Fig. 12 Plots of $\tan \delta$ and storage modulus $\mathrm{G}^{\prime}$ against temperature of PVA with $4 \%$ content of water and $\mathrm{MgCl}_{2} \cdot 6 \mathrm{H}_{2} \mathrm{O}$, respectively. 

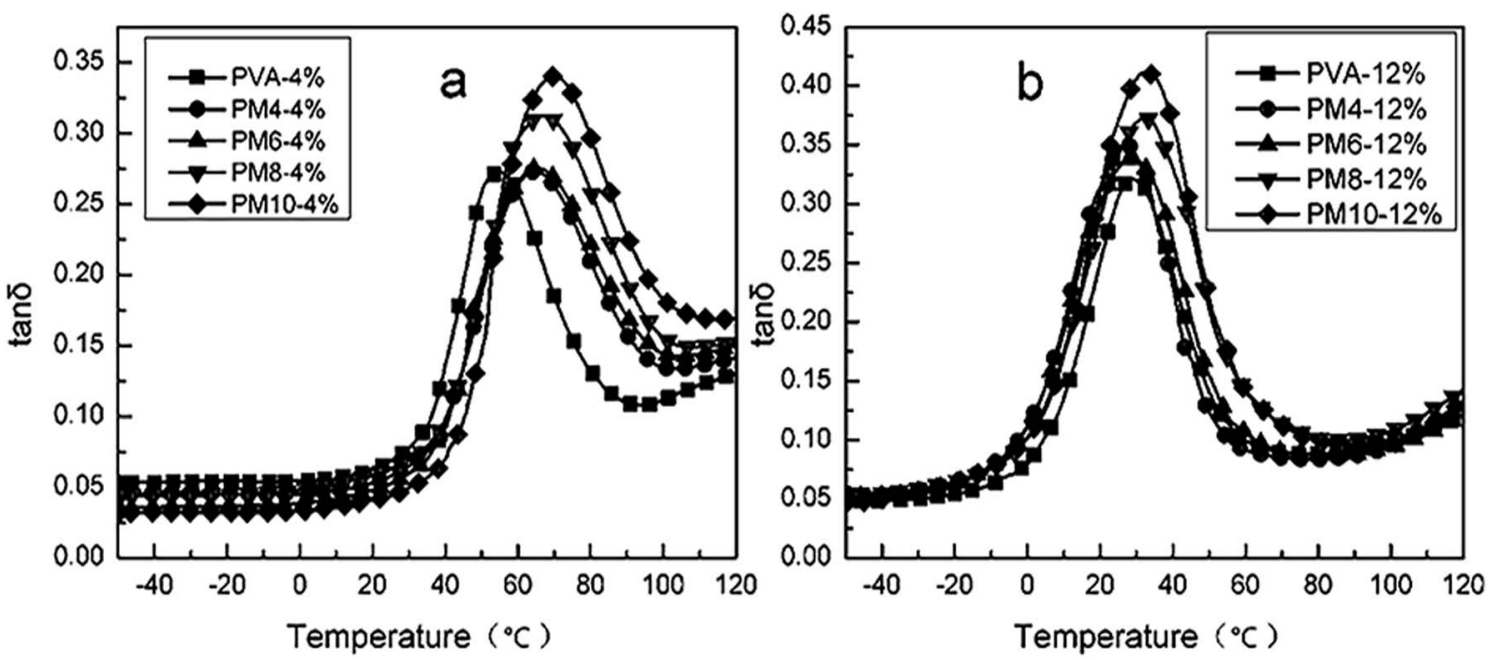

Fig. 13 Plots of $\tan \delta$ against temperature of PM with 4\% (a) and 12\% (b) water.

crosslink between $\mathrm{MgCl}_{2}$ and PVA was the key factor to increase strength. Thus, the slope of PVA1788 increased as the dosage of $\mathrm{MgCl}_{2}$ increased.

\section{Water sorption properties}

Due to the lots of -OH, PVA is hydrophilic. However, the compact crystal would prevent $\mathrm{H}_{2} \mathrm{O}$ from penetrating. ${ }^{4}$ As a result, the water absorption content of PVA depended on the rate of amorphous region. Fig. 10 showed the water absorption rate of PVA 1799 and PM10 at RH of 54\%. As shown in Fig. 10, the water content in PM10 was always higher than that of pure PVA, and the difference became larger with the time going. This proved that $\mathrm{MgCl}_{2}$ could destroy the crystal of PVA and increased the amorphous fraction resulting in the high water content in PM10. Meanwhile, the hydrophilicity of $\mathrm{MgCl}_{2}$ could also increase the water content of PM10. As a result, the water sorption of PM was higher than that of PVA.

The effect of water on dynamic mechanical properties of PVA1799 modified with $\mathrm{MgCl}_{2}$

$\mathrm{MgCl}_{2}$ could increase the water sorption of PVA. However, there were few studies on the effect of water on the modification of $\mathrm{MgCl}_{2}$ on PVA. Thence, the role of water in the modification was studied.

Fig. 11 showed the plots of storage modulus $\left(G^{\prime}\right)$ and $\tan \delta$ versus temperature of PVA1799 with $0,4 \%, 12 \%$ content of water. It could be seen from Fig. 11(a) that $T_{\mathrm{g}}$ of PVA decreased with the increasing content of water. While with $12 \%$ content of water, $T_{\mathrm{g}}$ decreased from $82{ }^{\circ} \mathrm{C}$ of fully dried PVA to $28{ }^{\circ} \mathrm{C}$. In addition, increasing water content could also decreased $G^{\prime}$ of PVA. This proved that water was an efficient plasticizer of PVA.

The effect of $\mathrm{MgCl}_{2} \cdot 6 \mathrm{H}_{2} \mathrm{O}$ and water on the dynamic mechanical properties of PVA were studied, respectively. As shown in Fig. 12, the $T_{\mathrm{g}}$ of PVA modified with $\mathrm{MgCl}_{2}$ was higher than that of PVA modified with the same content water. Meanwhile, $G^{\prime}$ of PM was lower than PVA modified with water at low temperature, but it reversed as the temperature increased. This was because that crystallinity was the major factor affecting $G^{\prime}$ when it was at lower temperature. The addition of $\mathrm{MgCl}_{2}$ would destroy the crystal of PVA. As a result, the storage modulus of PM was lower than PVA modified with water. With

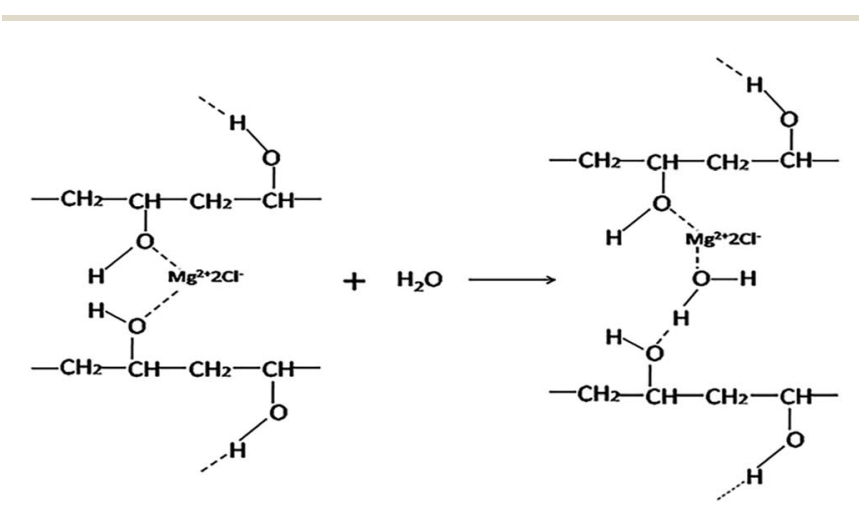

Fig. 14 The way of water damaging the interaction between PVA and $\mathrm{MgCl}_{2} \cdot 6 \mathrm{H}_{2} \mathrm{O}$.

Table 3 The difference of $T_{\mathrm{g}}$ values between PVA and PM with various content of water

The difference

\begin{tabular}{lllrl} 
of $T_{\mathrm{g}}$ & PM4 minus PVA & PM6 minus PVA & PM8 minus PVA & PM10 minus PVA \\
\hline $0 \%$ & $20.7{ }^{\circ} \mathrm{C}$ & $25.09{ }^{\circ} \mathrm{C}$ & $25.07{ }^{\circ} \mathrm{C}$ & $29.17^{\circ} \mathrm{C}$ \\
$4 \%$ & $10.48^{\circ} \mathrm{C}$ & $10.77^{\circ} \mathrm{C}$ & $12.65{ }^{\circ} \mathrm{C}$ & $15.53{ }^{\circ} \mathrm{C}$ \\
$12 \%$ & $-1.96^{\circ} \mathrm{C}$ & $-0.81{ }^{\circ} \mathrm{C}$ & $2.94{ }^{\circ} \mathrm{C}$ & $3.16^{\circ} \mathrm{C}$
\end{tabular}



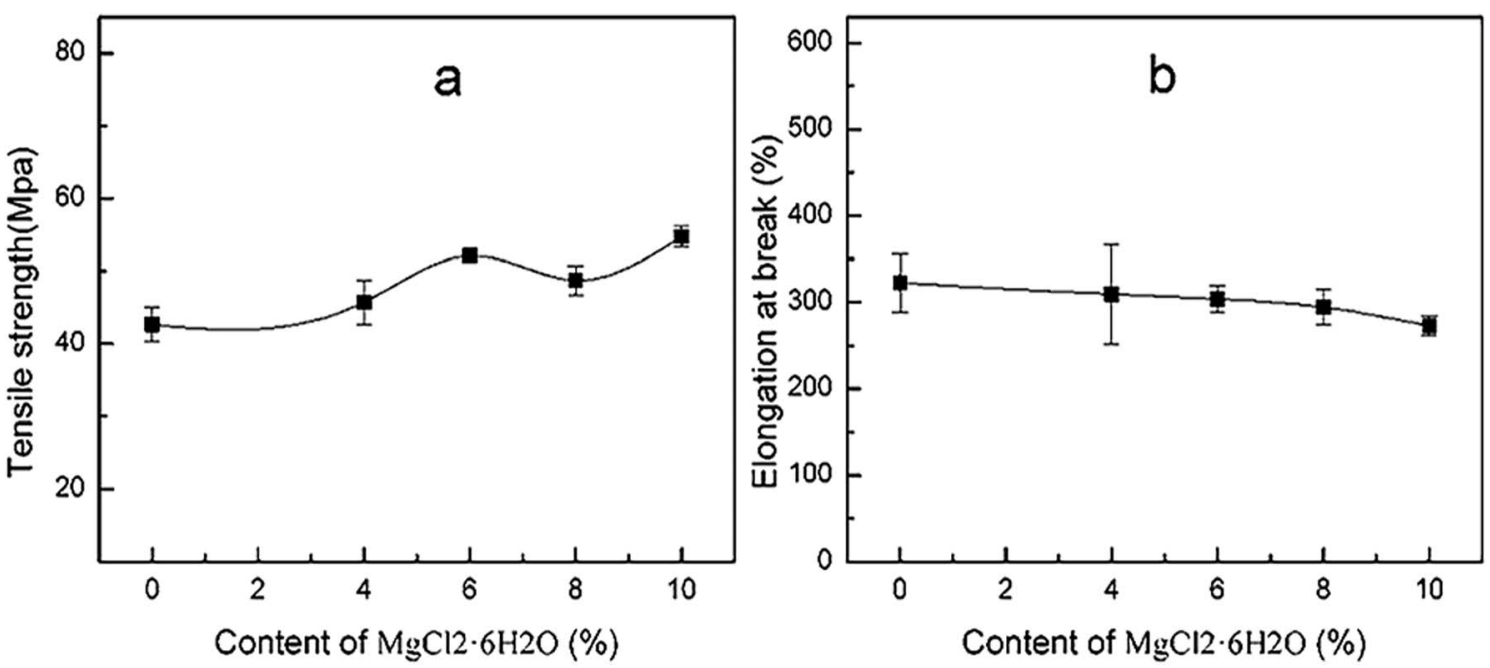

Fig. 15 The tensile strength (a) and elongation (b) at break of PVA with various contents of $\mathrm{MgCl}_{2} \cdot 6 \mathrm{H}_{2} \mathrm{O}$ in certain water content (12\%).

the increasing temperature, the crystal was destroyed and thus crystallinity had lower difference on the storage modulus. Thence, the crosslink between $\mathrm{Mg}^{2+}$ and PVA took an increasing impact on $G^{\prime}$. Therefore, $G^{\prime}$ of PM was higher than PVA modified with water as the temperature increased.

It could be seen from Fig. 13 that increasing dosage of $\mathrm{MgCl}_{2}$ could increase $T_{\mathrm{g}}$ of PVA in the presence of water. This indicated that $\mathrm{MgCl}_{2}$ still could crosslink with PVA. Table 3 showed the difference of the $T_{\mathrm{g}}$ between PM and PVA with the same content of water. Increasing water content decreased the difference with any content of $\mathrm{MgCl}_{2}$. This indicated that water could destroy the crosslink between $\mathrm{MgCl}_{2}$ and PVA. Oxygen atom of $\mathrm{H}_{2} \mathrm{O}$ could interact with $\mathrm{Mg}^{2+}$, which would hinder the crosslink between $\mathrm{Mg}^{2+}$ and PVA resulting in the increase of molecular segmental mobility. The way of water damaging the interaction between PVA and $\mathrm{MgCl}_{2}$ was shown as Fig. 14 With the $12 \%$ content water, both the difference between PM4 and PVA, PM6 and PVA were negative. This proved that the crosslink had been destroyed by water completely. In addition, $\mathrm{MgCl}_{2}$ existed as hydrated $\mathrm{MgCl}_{2}$ in the system which had larger size and could increase the free volume of PVA. As a result, both the $T_{\mathrm{g}}$ of PM4 and PM6 were lower than that of pure PVA.

\section{The effect of $\mathrm{MgCl}_{2}$ on mechanical properties of PVA1799 in the presence of water}

The effect of the dosage of $\mathrm{MgCl}_{2}$ on the tensile strength and elongation at break of PVA in $12 \%$ water content was shown in Fig. 15. It could be seen from Fig. 15(a) and 9(a) that the tensile strength of PVA modified with $\mathrm{MgCl}_{2}$ was $50 \mathrm{MPa}$ or so, but it could be over $120 \mathrm{MPa}$ after sufficient drying. This proved that water played a significant role in decreasing the strength of PVA modified with $\mathrm{MgCl}_{2}$. In addition, with the increasing $\mathrm{MgCl}_{2}$ content, the tensile strength of PVA increased, but the elongation at break decreased. This indicated that $\mathrm{MgCl}_{2}$ still could crosslink with PVA in the presence of water. However, the mechanical properties in Fig. 15 varied more slightly than that of PM after sufficient drying. This was might because that water could destroy the crosslink between $\mathrm{MgCl}_{2}$ and PVA resulting in the decrease of the enhancement of $\mathrm{MgCl}_{2}$ on PVA.

\section{Conclusion}

The various PVA films modified with $\mathrm{MgCl}_{2} \cdot 6 \mathrm{H}_{2} \mathrm{O}$ were prepared and the effect of $\mathrm{MgCl}_{2} \cdot 6 \mathrm{H}_{2} \mathrm{O}$ on PVA with different alcoholysis degree and polymerization degree were investigated. The modification mechanism of $\mathrm{MgCl}_{2}$ on PVA and the effect of water in this system were revealed. Basically, $\mathrm{MgCl}_{2}$ was an effective strengthening agent, which could crosslink with PVA and then effectively destroy the crystals of PVA. With the addition of $\mathrm{MgCl}_{2}$, the strength and rigidity of PVA increased significantly and the melting temperature decreased. The tensile strength of PVA films modified with $\mathrm{MgCl}_{2}$ were all over $120 \mathrm{MPa}$. The effect of $\mathrm{MgCl}_{2}$ on the thermal stability of PVA was related to the alcoholysis degree of PVA. $\mathrm{MgCl}_{2}$ could decrease the thermal stability of PVA with lower alcoholysis degree. In the case of high alcoholysis PVA, the effect was related to the polymerization degree of PVA. $\mathrm{MgCl}_{2}$ could increase the thermal stability of PVA with low polymerization degree. In addition, water could interact with $\mathrm{MgCl}_{2}$ to destroy the crosslink between $\mathrm{MgCl}_{2}$ and PVA resulting in the decrease of the enhancement of $\mathrm{MgCl}_{2}$ on PVA. Taken together, the above studies revealed that $\mathrm{MgCl}_{2}$ could interact with PVA to increase the strength and rigidity of PVA and could increase the water sorption properties of PVA; however, the presence of water could decrease the modification effect. The further cognize on the way of $\mathrm{MgCl}_{2}$ influencing PVA could do help in revealing the modification mechanism of other inorganic salts on PVA and preparing the materials with more excellent properties.

\section{Conflicts of interest}

The authors declare no conflict of interest. 


\section{Acknowledgements}

This research was supported by the National Natural Science Foundation of China (No. 51273129) and Applied Basic Research Project of Sichuan Province (No. 2017JY0247).

\section{References}

1 R. M. Hodge, T. J. Bastow, G. H. Edward, G. P. Simon and A. J. Hill, Macromolecules, 1996, 29, 8137-8143.

2 J. Jang and D. K. Lee, Polymer, 2003, 44, 8139-8146.

3 R. Gref, Z. H. Ping, Q. T. Nguyen, et al., Polymer, 1995, 36, 1655-1661.

4 G. J. Pritchard, Poly(vinyl alcohol): basic properties and uses, Macdonald Technical \& Scientific, 1970.

5 W. Q. Wu, H. F. Tian and A. Xiang, J. Polym. Environ., 2012, 20, 63-69.

6 H. M. Zidan, Polym. Test., 1999, 18, 449-461.

7 H. M. Zidan, J. Appl. Polym. Sci., 2003, 88, 516-521.

8 Z. Peng and D. Chen, J. Polym. Sci., Part B: Polym. Phys., 2006, 44, 534-540.

9 G. Vijaya Kumar and R. Chandramani, Appl. Surf. Sci., 2009, 255, 7047-7050.

10 R. Singh and S. G. Kulkarni, Int. J. Polym. Mater. Polym. Biomater., 2013, 62, 351-357.
11 J. I. Kubo, N. Rahman, N. Takahashi, T. Kawai, G. Matsuba, K. Nishida, T. Kanaya and M. Yamamoto, J. Appl. Polym. Sci., 2009, 112, 1647-1652.

12 X. C. Jiang, X. F. Zhang, D. Z. Ye, X. Zhang and D. Hua, Polym. Eng. Sci., 2012, 52, 1565-1570.

13 R. M. Hodge, G. H. Edward and G. P. Simon, Polymer, 1996, 37, 1371-1376.

14 G. Mann, Acta Polym., 1986, 37, 744-745.

15 R. Iwamoto, M. Miya and S. Mima, J. Polym. Sci., Part B: Polym. Phys., 1979, 17, 1507-1515.

16 R. M. Hodge, T. J. Bastow, G. H. Edward, et al., Macromolecules, 1996, 29, 8137-8143.

17 R. Wang, Q. Wang and L. Li, Polym. Int., 2003, 52, 1820-1826.

18 S. J. Peng, S. X. Liu, Y. J. Sun, N. P. Xiang, X. C. Jiang and L. X. Hou, Eur. Polym. J., 2018, 106, 206-213.

19 C. A. Finch, Polyvinyl alcohol: properties and applications, Wiley London, 1973.

20 P. D. Garrett and D. T. Grubb, J. Polym. Sci., Part B: Polym. Phys., 1988, 26, 2509-2523.

21 Y. Tsuchiya and K. Sumi, J. Polym. Sci., Part A-1: Polym. Chem., 1969, 7, 3151-3158.

22 P. Thomas, J.-P. Guerbois, G. Russell, et al., J. Therm. Anal. Calorim., 2001, 64, 501-508. 